\title{
Cream and albinotic - two new mutations affecting body colour in Pyrrhocoris apterus (Heteroptera: Pyrrhocoridae)
}

\author{
RADOMÍR SOCHA \\ Biology Centre ASCR, Institute of Entomology, Branišovská 31, CZ-370 05 České Budějovice, Czech Republic, \\ e-mail:socha@entu.cas.cz
}

Key words. Firebug, body-colour mutants, albinotic, cream, inheritance pattern, reproductive potential

\begin{abstract}
Two new body-colour mutations, albinotic (alb) and cream (cr) are isolated and described for the flightless wingpolymorphic bug, Pyrrhocoris apterus (L.). The body colour of alb mutants is white and that of $\mathrm{cr}$ mutants either a light cream or creamy yellow. Both the alb and $\mathrm{cr}$ mutations most probably inhibit the biosynthesis of the red pigment in epidermal cells that is responsible for the red-coloured body of wild-type bugs. Although sometimes the body colour of younger larval instars of $\mathrm{cr}$ mutants is a slightly darker creamy yellow and that of last larval instars of the alb mutants a slightly whiter greyish, there were no other important developmental changes in the body colour of alb and $\mathrm{cr}$ homozygous bugs associated with metamorphosis and postmetamorphic aging of adults. Standard genetic analyses showed that both these mutations are inherited as autosomal recessives and exhibit complete penetrance and uniform expression in both sexes. The fertility of the alb and $\mathrm{cr}$ homozygous females and fertilization success of the $a l b$ and $c r$ homozygous males were substantially lower than those of wild-type bugs.
\end{abstract}

\section{INTRODUCTION}

The firebug Pyrrhocoris apterus (L.) is a widely distributed palaearctic species of the heteropteran family Pyrrhocoridae, with the core of its distribution in the Mediterranean area and eastern and central Asia. It is characterized by a non-functional wing-polymorphism (Honěk, 1976; Socha, 1993) since both the long-winged (macropterous) and short-winged (brachypterous) specimens of this bug are flightless (Socha \& Zemek, 2000). In central Europe, the bug mostly lives at the foot of lime trees (Tilia cordata Miller, T. platyphylos Scopoli) and mainly feeds on their seeds (Socha, 1993). This bug is a convenient model insect because it is easy to rear in the laboratory. Socha (1993) gives a detailed account of the biology of $P$. apterus. The popularity of this insect as an experimental model for biological research is reflected in the large number of papers on this species. The firebug was successfully used to study hormonal regulation of mating success in males and maturation of their reproductive accessory glands (Socha, 2004, 2006; Socha \& Hodková, 2006), development and histolysis of nonfunctional flight muscles (Socha \& Šula, 2006, 2008) and for identifying the bug's native adipokinetic hormones and their stimulatory effects on walking activity (Socha et al., 1999; Kodrík et al., 2000, 2002a, b, 2003, 2010) and other important topics of insect physiology and behavioural endocrinology.

Description of chromatin elements in P. apterus by Henking (1891) was in fact the first report of sex chromosomes. Since then $P$. apterus has been intensively studied by insect physiologists and endocrinologists, but virtually ignored by geneticists. The genetics of $P$. apterus was not investigated until 1968, when the white (wh) mutation of this bug was first described and shown to cause the white- body colour of mutant specimens and inherited as a single autosomal recessive (Rizki \& Sláma, 1968). To date, the following pigment mutations and genetic strains of $P$. apterus are described and analysed: yellow (yw) (Socha, 1984; Sláma, 1998); reddish lobes (rl 17) (Socha, 1984); melanotic $(m)$ (Socha, 1984; Sláma, 1998); mosaic (mo) (Socha, 1987b); Pale (Pa) (Socha, 1988a); Apricot (Ap) (Socha, 1988b) and yolk body (yb) (Socha, 1997). These mutations affect the biosynthesis and deposition of pterines in epidermal cells or melanine pigments in the cuticle of $P$. apterus (Socha \& Němec, 1992, 1996; Porcar et al., 1996; Bel et al., 1997). The $y w, m$, and $y b$ mutations are inherited as single autosomal recessives, $\mathrm{Pa}$ and $A p$ as autosomal dominants, and the mo trait behaves as an unstable sex-linked recessive and is probably transposon-mediated (Socha et al., 1993).

The aim of the present study was to elucidate the mode of inheritance of the newly isolated albinotic (alb) and cream (cr) mutations of $P$. apterus, and to determine the reproductive potential of $a l b$ and $c r$ mutant males and females. The results increase the contemporary knowledge of the formal genetics and genetic regulation of body colour in P. apterus and provide new tools for chromatographic studies on the biosynthesis of pteridines.

\section{MATERIAL AND METHODS}

\section{Experimental conditions}

The wild-type bugs were collected from a population located in České Budějovice, Czech Republic $\left(48^{\circ} 59^{\prime} \mathrm{N}, 14^{\circ} 28^{\prime} \mathrm{E}\right)$. All stages from egg to adult were reared under a long-day (18L: 6D) photoperiod and a constant temperature of $26 \pm 1{ }^{\circ} \mathrm{C}$, which allow the bugs to breed continuously. Under these conditions, the wild type and mutant stocks required approximately 1 month to develop from egg to adult. Larvae and adults of all stocks were kept in glass jars $(0.51)$ in mass culture (approximately 40 
specimens per jar) and supplied with linden seeds (Tilia cordata) and water ad libitum, which was replenished twice a week. The water was supplied in small glass tubes plugged with cotton wool. More details of the breeding of the firebug are described elsewhere (Socha \& Šula, 1996; Socha et al., 1997). For each genetic cross, several single pairs and mass matings were established. Matings of single pairs and mass matings were made in individual Petri dishes $(\varnothing=6 \mathrm{~cm})$ and 0.51 glass jars, respectively, supplied with linden seeds and water in glass tubes plugged with cellulose wool.

\section{Isolation of alb and $c r$ mutations}

Stocks of the wild-type specimens and the alb and $\mathrm{cr}$ mutants of Pyrrhocoris apterus were used in the present study. The alb and $\mathrm{cr}$ mutant stocks were established in 1997 with 5-7 mutant specimens that occurred spontaneously among the $F_{2}$ progeny from a wild population of $P$. apterus collected in the vicinity of České Budějovice, Czech Republic ( $\left.48^{\circ} 59^{\prime} \mathrm{N}, 14^{\circ} 28^{\prime} \mathrm{E}\right)$. In succeeding generations, approximately $20-30$ pairs of mutant individuals were used for mass mating to establish the alb and $\mathrm{cr}$ mutant stocks. Adults of the fifth generation of both wild-type and mutant strains were used for genetic crosees. Freshly ecdysed wild-type and mutant adult bugs were separated according to sex and placed in groups of 10-20 specimens in small glass jars $(250 \mathrm{ml})$ and kept under the same photoperiodic and temperature regime in which they had developed. They were supplied with linden seeds and water. After reaching a required age, adult males and females homozygous for alb and cr genes were used for analysis of reproductive potential and determining the pattern of inheritance of these traits.

\section{Analysis of reproductive potential of the alb and $\mathrm{cr}$ mutants}

For the comparison of the reproductive capacity of the alb and $\mathrm{cr}$ homozygous females with that of wild-type females, used as controls, the first five successive egg batches laid by individual mutant and wild-type females of a particular cross were collected and the number of eggs per batch and their hatchability determined. Five days old reproductively active females, i.e. those at their highest attractiveness and receptivity (Žd'árek, 1970) were used in the fertility tests. For the comparison of the fertilization success of the alb and $c r$ homozygous males with that of wild-type males, used as controls, the first five successive egg batches laid by wild-type females inseminated individually by one of the 11-14 males of the alb or $\mathrm{cr}$ homozygous mutants were collected and their average hatchability assessed.

Adult males and females from all crosses tested were virgins and used only once. Egg laying and mortality of parents were checked daily. Sterile or unfertilised eggs that did not yield larvae were categorized as unhatched.

\section{Standard genetic analyses}

To determine the mode of inheritance of the alb and $c r$ traits, standard reciprocal genetic crosses between alb and wild-type bugs and between $\mathrm{cr}$ and wild-type bugs were performed. Both kinds of matings were done under a long-day $(18 \mathrm{~L}: 6 \mathrm{D})$ photoperiod and a constant temperature of $26 \pm 1{ }^{\circ} \mathrm{C}$. Progenies derived from these crosses $\left(\mathrm{P}_{1}, \mathrm{~F}_{1}\right.$ and backcrosses) were classified by sex and phenotype in the 4th or 5th larval instars. The $a l b, c r$, and wild-type phenotypes were expressed uniformly in both sexes within each set of crosses. Since there were no significant differences in sex ratio in these crosses, except for a slight tendency for males to prevail in most of crosses, the data obtained for both sexes were combined. The results of phenotypic evaluations obtained for each cross of standard genetic crosses were analysed statistically by chi-square for goodnessof-fit.

\section{Data presentation and statistical analyses}

Arithmetic means of the results are presented throughout the paper. Statistics were computed using the software GraphPad Prism, version 4.0 (San Diego, CA, U.S.A.). A one-way analysis of variance (ANOVA) followed by the Tukey's multiple comparison tests was used to compare the numbers of eggs in batches and their hatchability among the experimental groups determined. The results of phenotypic evaluations obtained for each of the standard genetic crossess were analysed statistically by chi-square for goodness-of-fit.

\section{RESULTS}

\section{Morphology of the alb and $\boldsymbol{c r}$ mutants of $P$. apterus}

The $a l b$ and $c r$ individuals of $P$. apterus are clearly distinguishable from the wild-type bugs as they differ in the pattern of their body pigmentation (Fig. 1). Unlike the red-coloured wild-type larvae (Fig. 1C) and adults (Fig. $1 \mathrm{~F}$ ), the colour of the bodies of alb mutant larvae (Fig. 1A) and adults (Fig. 1D) is white and that of $\mathrm{cr}$ mutant larvae (Fig. 1B) and adults (Fig. 1E) ranged from a light cream to creamy yellow colour. Thus, larvae and adults with both the alb and $c r$ mutations are characterized by the lack of red pigment in the epidermal cells, and as a consequence the non-melanized parts of their bodies are either white or creamy yellow, respectively, in contrast to the red colour typical of wild-type bugs. No other important developmental changes in body colouration of the alb and $\mathrm{cr}$ homozygous bugs associated with metamorphosis and post-metamorphic aging of adults were observed, except sometimes the young larval instars of the $\mathrm{cr}$ mutants had a slightly darker creamy yellow colour and the last larval instar of the alb mutant were slightly tinged with a whitish-greyish colour. Both mutant phenotypes were expressed uniformly in both sexes.

\section{Reproductive potential of $a l b$ and $c r$ homozygous males and females}

The reproductive capacity of the alb and $\mathrm{cr}$ mutants and that of the wild-type bugs, including the average number of eggs per batch and their average hatchability, is presented in Table 1.

The ANOVA revealed that batches of eggs laid by the alb (cross B) and $c r$ (cross C) mutant pairs contained significantly $(P<0.01)$ fewer eggs than those laid by the wild-type pairs of the same age (cross A), but no significant difference in the average numbers of eggs laid by the $a l b$ and $\mathrm{cr}$ mutant pairs. This indicates that the reproductive potential of both the $a l b$ and $c r$ mutants is substantially lower than that of wild-type bugs. However, no significant differences were found in the average numbers of eggs laid by reciprocal crosses between alb males and wild-type females (cross D), and between the alb females and wild-type males (cross E), which indicates that both sexes are responsible for the lower reproductive capacity of the alb mutants. The average number of eggs per batch produced by both reciprocal crosses between $\mathrm{cr}$ males and wild-type females (cross F), and between $\mathrm{cr}$ females and wild-type males (cross $\mathrm{G}$ ) was significantly lower $(P$ $<0.01$ ) than in those laid by wild-type pairs (cross A). Despite this fact, the significant differences $(P<0.05)$ 

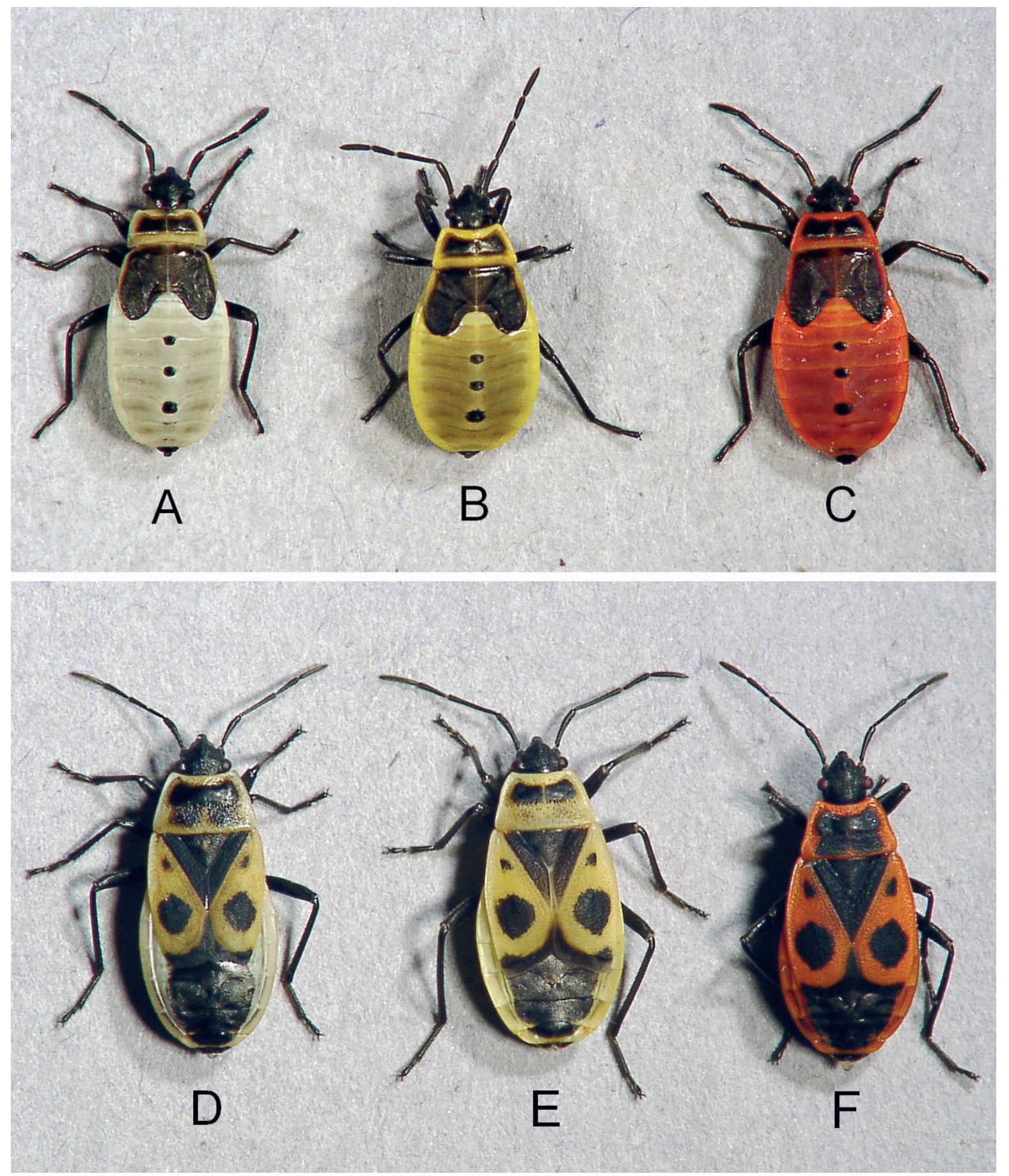

Fig. 1. The wild-type, albinotic, and cream mutant specimens of Pyrrhocoris apterus. A - 5th instar larva of the albinotic mutation; B - 5th instar larva of the cream mutation; $\mathrm{C}$ - 5th instar larva of the wild-type phenotype; D - adult of the albinotic mutation; $\mathrm{E}$ - adult of the cream mutation; $\mathrm{F}$ - adult of the wild-type phenotype.

between the average numbers of eggs laid by wild-type females mated with $c r$ males (cross F) and those laid by $\mathrm{cr}$ females mated with wild-type males (cross $\mathrm{G}$ ) indicate that it is mainly the homozygous $\mathrm{cr}$ female that is responsible for the lower reproductive potential of $\mathrm{cr}$ mutants.

The ANOVA also revealed that the average hatchability of eggs laid by alb mutant pairs (cross B) and $\mathrm{cr}$ pairs (cross C) was significantly $(P<0.01)$ lower than that of eggs laid by wild-type pairs of the same age (cross A). Like the average numbers of eggs, there were no signifi- cant differences in the average hatchability of eggs laid by the $a l b$ and $c r$ mutant pairs (crosses B and C). These results indicate that not only the production but also the hatchability of eggs laid by the $a l b$ and $c r$ pairs was substantially lower than that of the eggs laid by wild-type pairs. Since no significant differences were found in the average hatchability of eggs laid by reciprocal crosses between alb males and wild-type females (cross D) and between alb females and wild-type males (cross E), it is likely that both sexes are responsible for the lower hatch- 
TABLE 1. Comparison of the reproductive potential of albinotic, cream and wild-type adults of P. apterus.

\begin{tabular}{cccccc}
\hline Cross code & \multicolumn{2}{c}{$\begin{array}{c}\text { Cross } \\
\text { Female } \times \text { Male }\end{array}$} & No. of pairs & $\begin{array}{c}\text { No. of eggs per batch } \\
(\text { mean } \pm \text { SD) }\end{array}$ & $\begin{array}{c}\text { Hatchability of eggs (in \%) } \\
(\text { mean } \pm \text { SD) }\end{array}$ \\
\hline A & WT & WT & 12 & $68.45 \pm 6.98$ & $68.58 \pm 20.90$ \\
B & $a l b$ & $a l b$ & 13 & $44.46 \pm 9.92$ & $16.20 \pm 14.71$ \\
C & $c r$ & $c r$ & 8 & $31.06 \pm 9.82$ & $13.43 \pm 19.69$ \\
D & WT & $a l b$ & 11 & $46.04 \pm 12.89$ & $42.96 \pm 26.49$ \\
E & $a l b$ & WT & 29 & $39.11 \pm 9.58$ & $29.96 \pm 31.38$ \\
F & WT & $c r$ & 14 & $46.46 \pm 13.79$ & $36.78 \pm 35.41$ \\
G & $c r$ & WT & 14 & $33.70 \pm 13.12$ & $28.32 \pm 21.54$ \\
\hline
\end{tabular}

Abbreviations and explanations: WT - wild-type bugs; alb - homozygous albinotic mutants; cr - homozygous cream mutants. Number of eggs and egg hatchability were determined separately for each egg batch, but because there were no significant differences between the 5 consecutive batches laid by individual pairs of bugs, the results were averaged. Approximately $2500-3200$ eggs for each cross were analysed.

ability of these eggs. Both sexes are responsible also for the lower hatchability of eggs obtained from the reciprocal crosses between $\mathrm{cr}$ males and wild-type females (cross F), and $c r$ females and wild-type males (cross G), since there were no significant differences in the average hatchability of eggs obtained from these crosses. Since the fertilization tests showed that the hatchability of eggs laid by wild-type females fertilized by either alb or $\mathrm{cr}$ males was lower than that of wild-type females of the same age fertilized by wild-type males, it is likely that fertilization success of $a l b$ and $c r$ mutant males is lower than that of wild-type males. Thus, the above results revealed that homozygous sets of $a l b$ and $c r$ genes are responsible for both the lower fertility of alb and $\mathrm{cr}$ females and lower fertilization success of alb and $\mathrm{cr}$ males.

\section{Pattern of inheritance of the $a l b$ and $c r$ traits}

Standard genetic crosses were used to assess the pattern of inheritance of the alb and $c r$ mutations. The results of mating wild-type pairs and alb homozygous mutant pairs (crosses A and B, respectively) are presented in Table 2.

Significantly fewer offspring resulted from cross B than cross A. This confirmed the lower reproductive potential of the alb mutants recorded in Table 1 (cross A and B). Both reciprocal $P_{1}$ crosses (crosses $C$ and $D$ ) resulted in $F_{1}$ progenies containing only individuals with the wild-type phenotype. When $\mathrm{F}_{1}$ progenies were intercrossed (crosses $\mathrm{E}$ and F), the wild-type and $a l b$ phenotypes segregated in a ratio of $3: 1$ in favour of wild-type bugs. This indicates that the alb trait is under control of a single autosomal gene. The recessive character of the alb mutation was confirmed also by the reciprocal backcrosses (crosses G, I and $\mathrm{M}$ ), giving a $1: 1$ ratio between the wild-type and $a l b$ bugs, independent of their sex. A marginally significant departure from the expected $1: 1$ ratio in one of the reciprocal backcrosses (cross $\mathrm{K}$ ) was probably due to the lower viability of the homozygous alb individuals. Besides decreased viability of alb individuals found in cross $\mathrm{K}$ and lowered reproductive potential of the $a l b$

TABLE 2. Segregation of phenotypes between albinotic and wild-type individuals among the progeny of various crosses performed in the study of the inheritance of albinotic trait in P. apterus.

\begin{tabular}{|c|c|c|c|c|c|c|c|}
\hline \multirow{3}{*}{$\begin{array}{l}\text { Cross } \\
\text { code }\end{array}$} & \multirow{3}{*}{ No. of pairs } & & & \multicolumn{2}{|c|}{ Phenotype of progeny } & \multirow{2}{*}{\multicolumn{2}{|c|}{$\begin{array}{c}\frac{\chi^{2} \text { value }}{\text { WT }: a l b} \\
\end{array}$}} \\
\hline & & \multirow{2}{*}{\multicolumn{2}{|c|}{ Female $\times$ Male }} & \multirow{3}{*}{$\frac{\text { WT }}{1998}$} & \multirow{3}{*}{$\begin{array}{c}a l b \\
0\end{array}$} & & \\
\hline & & & & & & $1: 1$ & $3: 1$ \\
\hline $\mathrm{A}$ & 12 & WT & WT & & & & \\
\hline $\mathrm{B}$ & 13 & $a l b$ & $a l b$ & 0 & 389 & & \\
\hline $\mathrm{C}$ & 11 & WT & $a l b$ & 1164 & 0 & & \\
\hline $\mathrm{D}$ & 29 & alb & WT & 778 & 0 & & \\
\hline $\mathrm{E}$ & 12 & $\mathrm{~F}_{1}(\mathrm{C})$ & $\mathrm{F}_{1}(\mathrm{C})$ & 1220 & 366 & & 3.1282 \\
\hline $\mathrm{F}$ & 12 & $F_{1}(D)$ & $F_{1}(D)$ & 685 & 214 & & 0.6856 \\
\hline $\mathrm{G}$ & 11 & $\mathrm{~F}_{1}(\mathrm{C})$ & $a l b$ & 470 & 441 & 0.9232 & \\
\hline $\mathrm{H}$ & 14 & $\mathrm{~F}_{1}(\mathrm{C})$ & WT & 1867 & 0 & & \\
\hline I & 16 & $a l b$ & $F_{1}(C)$ & 317 & 308 & 0.1296 & \\
\hline $\mathrm{J}$ & 13 & WT & $\mathrm{F}_{1}(\mathrm{C})$ & 2281 & 0 & & \\
\hline $\mathrm{K}$ & 12 & $\mathrm{~F}_{1}(\mathrm{D})$ & $a l b$ & 306 & 258 & $4.0851^{*}$ & \\
\hline $\mathrm{L}$ & 12 & $\mathrm{~F}_{1}(\mathrm{D})$ & WT & 2480 & & & \\
\hline M & 25 & $a l b$ & $\mathrm{~F}_{1}(\mathrm{D})$ & 117 & 122 & 0.1046 & \\
\hline $\mathrm{N}$ & 22 & WT & $F_{1}(D)$ & 725 & 0 & & \\
\hline
\end{tabular}

Abbreviations and explanations: WT - wild-type bugs; alb - homozygous albinotic mutants; $\mathrm{F}_{1}$ - females or males of the 1st generation. * - Significantly different from the expected value (at the $5 \%$ significance level) evaluated by Chi-square test. 
TABLE 3. Segregation of phenotypes between cream and wild-type individuals among the progeny of various crosses performed in the study of the inheritance of cream trait in P. apterus.

\begin{tabular}{|c|c|c|c|c|c|c|c|}
\hline \multirow{3}{*}{$\begin{array}{l}\text { Cross } \\
\text { code }\end{array}$} & \multirow{3}{*}{ No. of pairs } & & & \multicolumn{2}{|c|}{ Phenotype of progeny } & \multicolumn{2}{|c|}{$\chi^{2}$ value } \\
\hline & & \multirow{2}{*}{\multicolumn{2}{|c|}{ Female $\times$ Male }} & \multirow{2}{*}{ WT } & \multirow{2}{*}{$\mathrm{cr}$} & \multicolumn{2}{|c|}{$\mathrm{WT}: c r$} \\
\hline & & & & & & $1: 1$ & $3: 1$ \\
\hline A & 10 & WT & WT & 1204 & & & \\
\hline $\mathrm{B}$ & 10 & $c r$ & $\mathrm{cr}$ & 0 & 20 & & \\
\hline $\mathrm{C}$ & 14 & WT & $c r$ & 994 & 0 & & \\
\hline $\mathrm{D}$ & 14 & $c r$ & WT & 630 & 0 & & \\
\hline $\mathrm{E}$ & 11 & $\mathrm{~F}_{1}(\mathrm{C})$ & $\mathrm{F}_{1}(\mathrm{C})$ & 1274 & 374 & & $4.6731^{*}$ \\
\hline $\mathrm{F}$ & 11 & $F_{1}(D)$ & $F_{1}(D)$ & 1127 & 349 & & 1.4453 \\
\hline $\mathrm{G}$ & 12 & $\mathrm{~F}_{1}(\mathrm{C})$ & $\mathrm{cr}$ & 1197 & 1155 & 0.7500 & \\
\hline $\mathrm{H}$ & 10 & $F_{1}(C)$ & WT & 969 & 0 & & \\
\hline I & 9 & $\mathrm{cr}$ & $\mathrm{F}_{1}(\mathrm{C})$ & 209 & 176 & 2.8286 & \\
\hline $\mathrm{J}$ & 9 & WT & $\mathrm{F}_{1}(\mathrm{C})$ & 1077 & 0 & & \\
\hline $\mathrm{K}$ & 14 & $F_{1}(D)$ & $c r$ & 868 & 780 & $4.6990 *$ & \\
\hline $\mathrm{L}$ & 12 & $F_{1}(D)$ & WT & 1861 & 0 & & \\
\hline M & 12 & $c r$ & $F_{1}(D)$ & 523 & 439 & $7.3347^{*}$ & \\
\hline $\mathrm{N}$ & 10 & WT & $F_{1}(D)$ & 1382 & & & \\
\hline
\end{tabular}

Abbreviations and explanations: WT - wild-type bugs; $c r$ - homozygous cream mutants; $\mathrm{F}_{1}$ - females or males of the 1st generation. * - Significantly different from the expected value (at the $5 \%$ significance level) evaluated by Chi-square test.

mutants, no other pleiotropic effects of alb locus on the larval development and adult life were observed.

The results of mating wild-type individuals and $\mathrm{cr}$ homozygous mutant bugs (crosses $\mathrm{A}$ and $\mathrm{B}$, respectively) are presented in Table 3 . In comparison to cross A, only a few $c r$ individuals were obtained in cross $\mathrm{B}$, which indicates that the $\mathrm{cr}$ mutants have a low reproductive potential. Both reciprocal $\mathrm{P}_{1}$ crosses (crosses $\mathrm{C}$ and $\mathrm{D}$ ) resulted in $F_{1}$ progenies containing only individuals of the wildtype phenotype. When $F_{1}$ progenies were intercrossed (crosses $\mathrm{E}$ and F), the wild-type and $c r$ phenotypes segregated in a ratio of $3: 1$ in favour of wild-type bugs. These results indicate that the $c r$ trait is controlled by a single autosomal recessive gene. The small, but significant departure from the expected $3: 1$ ratio in one of the intercrosses (cross E) was most probably due to the lower viability of the homozygous $\mathrm{cr}$ individuals. The autosomal recessive character of the $\mathrm{cr}$ mutation was confirmed by reciprocal backcross $\mathrm{I}$, resulting in a $1: 1$ ratio of wild-type to $c r$ bugs in the offspring, independent of their sex. The significant departures from the expected $1: 1$ ratio in reciprocal backcrosses $\mathrm{K}$ and $\mathrm{M}$ was due to the lower viability of the $c r$ homozygous bugs. Thus, in addition to the lower fertilization success of $\mathrm{cr}$ homozygous males and the low fertility of $\mathrm{cr}$ homozygous females, the $c r$ locus is also associated with the lower viability of the homozygous $\mathrm{cr}$ individuals.

\section{DISCUSSION}

\section{Pattern of inheritance of $a l b$ and $c r$ mutations and their effect on reproductive potential}

The present paper describes the morphology and pattern of inheritance of two newly isolated body-colour mutations (alb and $c r$ ) in $P$. apterus. The present study indicates that both of these mutations are inherited as autosomal recessives and exhibit complete penetrance and uniform expression in both sexes. Considering previous studies on the formal genetics of $P$. apterus, the alb and $\mathrm{cr}$ mutations are the fifth and sixth autosomal recessive mutations inhibiting the synthesis of red pigment in the body of this heteropteran. Like most of the other bodycolour mutations in P. apterus, the $a l b$ and $\mathrm{cr}$ mutations appeared spontaneously in cultures following the transfer of individuals from wild populations to the laboratory. They were probably present in the wild populations and revealed by the inbreeding that occurred in the small laboratory colonies or induced by sudden changes in some environmental cues, e.g. photoperiod or temperature.

The white-coloured body of larvae and adults of $P$. apterus with the alb mutation resembles the body colour of the previously described $w h$ mutant of this species (Rizki \& Sláma, 1968). Despite the fact, that both the $a l b$ and $w h$ mutations in P. apterus cause white colouration of the body, inhibit the synthesis of red pigment in epidermal cells and are inherited as single autosomal recessives, the reciprocal crosses between the alb/alb and $w h / w h$ mutants yielded only red-pigmented bugs in the $\mathrm{F}_{1}$ generation, which indicates that $a l b$ and $w h$ are different genes (Socha, unpubl. data).

The cream or creamy yellow colour of freshly hatched first instar larvae of $P$. apterus with the $\mathrm{cr}$ mutation is somewhat similar to that of first instar larvae with the $\mathrm{Pa}$ mutation (Socha, 1988a), but in the second, third, and fourth larval instars the body colour of $\mathrm{Pa}$ mutants is much deeper - usually dark yellow-orange (Socha, 1997). However, the $\mathrm{cr}$ and $\mathrm{Pa}$ bugs differ mainly in the pigmentation of their eyes, which is a creamy yellow in the $\mathrm{cr}$ mutants and not red-pigmented as in the $\mathrm{Pa}$ mutant bugs. Unlike the autosomal recessive character of the $\mathrm{cr}$ mutation in $P$. apterus, the $P a$ mutation is inherited as an autosomal dominant and characterized by post-blastokinesis lethality in $\mathrm{Pa} / \mathrm{Pa}$ homozygous males and females. The 
body colour of young larval instars of some $\mathrm{cr}$ mutants are more yellow than cream-coloured and may slightly resemble the larvae of the $y w$ mutation of $P$. apterus. However, the yellow body of the $y w$ larvae is usually more intense and much darker. Moreover, preliminary results indicate that the recessive $y w$ locus is not situated on the same autosome as the $c r$ locus (data not shown).

The body colour of individuals of $P$. apterus with the autosomal recessive $y b$ mutation (Socha, 1997) differ from that of individuals of the $\mathrm{cr}$ mutation as it is a yolklike colour, except the eyes, which are red as in wild-type bugs. Moreover, the body colour, particularly that of the forewings of old homozygous $y b$ adults changes from yolk-orange to orange-brick-red. Unlike to the $y b$ mutants, there are no similar developmental changes in body colour associated with metamorphosis and postmetamorphic aging of adults in the $\mathrm{cr}$ and alb homozygous bugs.

In addition to the body-colour mutants, including the newly described the alb and $\mathrm{cr}$ mutations, several other mutations and strains of $P$. apterus are reported, e.g. mutations affecting the course of choriogenesis (Socha, 1988c), embryogenesis (Socha \& Matolín, 1985), metamorphosis (Socha, 1987a), wing length (Honěk, 1986; Socha et al., 1993; Socha, 1995), and diapause behaviour (Socha \& Hodková, 1994). Despite the fact that the formal genetics of $P$. apterus is just beginning to be studied and it is necessary to isolate and characterize other visible genetic markers in this species, some of the body-colour mutations have been already successfully used as markers for studying hormone persistence in the body (Sláma \& Socha, 1979), genetic control of biosynthesis of pteridines (Socha \& Němec, 1992, 1996; Porcar et al., 1996; Bel et al., 1997), determination of sperm utilization in multiple mating of females (Socha, 1993) and sperm competition (Schöfl \& Taborsky, 2002; Socha, unpubl. data). The present study is therefore an important contribution to the formal genetics of $P$. apterus and an increase in the bank of mutations of this bug that can be used as useful tools in future biological studies.

In addition to the lower fertility of $a l b$ and $\mathrm{cr}$ homozygous females, the fertilization success of alb and $\mathrm{cr}$ homozygous males of newly isolated mutant stocks is also more or less lower, but the reason for this is unknown. It can be speculated that either the transfer of fewer sperm or less viable sperm, or aberrations in the pattern or transfer of seminal fluid might underlie the low fertilization success of the $a l b$ and $c r$ homozygous males compared to wild-type males of the same age. It is reported that it is the amount of secretion transferred from the male accessory glands to female reproductive tracts and not the sperm load that determines the higher fertilization success of young brachypterous males compared with macropterous males in P. apterus (Socha, 2006; Socha et al., 2004). It cannot be excluded that the same phenomenon might be partly responsible also for the low fertilization success of the alb and $c r$ homozygous males. This suggestion accords well with the knowledge that the components of male seminal fluid act in many ways to maximize a male's reproductive success and are important for the viability and survival of sperm in the reproductive tract of the females (for reviews see e.g. Tram \& Wolfner, 1999; Wolfner, 2002; Gillott, 2003; Kubli, 2003; Chapman \& Davies, 2004; Poiani, 2006). Mating behaviour of $P$. apterus males (Socha, 2006) and those of D. melanogaster (Wilson et al., 2003) is regulated by juvenile hormone, either directly or indirectly, by a component in the secretion of the male accessory gland. In $P$. apterus, the significantly greater amount of juvenile hormone-dependent $53-\mathrm{kDa}$ glycoprotein in the accessory glands of 3-14 days-old brachypterous males than in macropterous males of the same age is thought to result in a more efficient sperm storage and fertilization of females (Socha et al., 2004). It is likely that different amounts of this and/or some other specific protein in the accessory gland secretion transferred by males might be partially responsible for the low fertilization success of alb and $\mathrm{cr}$ mutant males.

\section{The effects of $a l b$ and $c r$ mutations on the biosynthesis of pteridines}

It is very probable that both the alb and $c r$ mutations, described for the first time in the present paper, also negatively effect the biosynthesis and/or deposition of erythropterine and other pteridines in epidermal cells that are responsible for the dark yellow and red colouration of the body of wild-type individuals of this bug, in a similar way to the $w h$ and $y w$ mutations of $P$. apterus (Porcar et al., 1996; Bell et al., 1997). Only a few body-colour mutations are reported for Heteroptera and very little is known about pteridine biosynthesis, since only a few species have been studied in this respect (Berridge, 1965; Merlini \& Nasini, 1966; Smith \& Forrest, 1969; Lawrence, 1970; Halfenberg \& Stein, 1971; Hollweg, 1972; Smith \& Forrest, 1976; Melber \& Schmidt, 1992, 1994; Shimizu \& Kawasaki, 2001). Thus, future chromatographic studies on pteridines present in alb and $\mathrm{cr}$ mutants of $P$. apterus should extend our knowledge on the biochemistry and genetics of the pteridine pathway in insects.

ACKNOWLEDGEMENTS. This study was funded by grant No. P501/10/1215 from the Czech Science Foundation (DK) and Institute of Entomology project No. Z50070508. The author thanks D. Rienesslová for technical assistance.

\section{REFERENCES}

Bel Y., Porcar M., Socha R., Němec V. \& Ferré J. 1997: Analysis of pteridines in Pyrrhocoris apterus (L.) (Heteroptera, Pyrrhocoridae) during development and in body-color mutants. Arch. Insect Biochem. Physiol. 34: 83-98.

BERRIDGe M.J. 1965: The physiology of excretion in the cotton stainer Dysdercus fasciatus Signoret. J. Exp. Biol. 43: 511-521.

Chapman T. \& Davies S.J. 2004: Functions and analysis of the seminal fluid proteins of male Drosophila melanogaster fruit flies. Peptides 25: 1477-1490.

GiLlott C. 2003: Male accessory gland secretions: Modulators of female reproductive physiology and behavior. Annu. Rev. Entomol. 48: 163-184. 
Halfenberg R. \& Stein G. 1971: Über das rote pigment der baumwollwanze Dysdercus intermedius Dist. Z. Naturf. 26b: 71.

HenKING H. 1891: Untersuchungen über die ersten Entwicklungsvorgänge in den Eiern der Insekten. Über Spermatogenese und deren Beziehung zur Entwicklung bei Pyrrhocoris apterus L. Z. Wiss. Zool. 51: 685-736.

Hollweg G. 1972: Eine neue farbmuster-mutante "white" der roten baumwollwanze Dysdercus intermedius Dist. (Heteroptera, Pyrrhocoridae). Biol. Zbl. 91: 545-556.

HonĚK A. 1976: The regulation of wing polymorphism in natural populations of Pyrrhocoris apterus (Heteroptera, Pyrrhocoridae). Zool. Jb. Syst. 103: 547-570.

HoNĚK A. 1986: Inheritance of wing form in Pyrrhocoris apterus. J. Hered. 77: 465-467.

Kodrík D., Socha R., Šimek P., Zemek R. \& Goldsworthy G.J. 2000: A new member of the AKH/RPCH family that stimulates locomotory activity in the firebug, Pyrrhocoris apterus (Heteroptera). Insect Biochem. Mol. Biol. 30: 489-498.

Kodrík D., Socha R. \& ZemeK R. 2002a: Topical application of Pya-AKH stimulates lipid mobilization and locomotion in the flightless bug, Pyrrhocoris apterus (L.) (Heteroptera). Physiol. Entomol. 27: 15-20.

Kodrík D., ŠImeK P., Lepša L. \& Socha R. 2002b: Identification of the cockroach neuropeptide Pea-CAH-II as a second adipokinetic hormone in the firebug Pyrrhocoris apterus. Peptides 23: 585-587.

Kodrík D., Socha R. \& Syrová Z. 2003: Developmental and diel changes of adipokinetic hormone in CNS and haemolymph of the flightless wing-polymorphic bug, Pyrrhocoris apterus (L.). J. Insect Physiol. 49: 53-61.

Kodrík D., Alquicer G. \& Socha R. 2010: Methoprene modifies adipokinetic hormone characteristics in the firebug Pyrrhocoris apterus (Heteroptera: Pyrrhocoridae). Eur. J. Entomol. 107: 33-39.

Kubli E. 2003: Sex-peptides: seminal peptides of the Drosophila male. Cell. Mol. Life Sci. 60: 1689-1704.

LAWRENCE P.A. 1970: Some new mutants of the large milkweed bug Oncopeltus fasciatus Dall. Genet. Res. 15: 347-350.

Melber C. \& Schmidt G.H. 1992: Identification of fluorescent compounds in certain species of Dysdercus and some of their mutants (Heteroptera, Pyrrhocoridae). Comp. Biochem. Physiol. (B) 101: 115-133.

Melber C. \& Schmidt G.H. 1994: Quantitative variations in the pteridines during the post-embryonic development of Dysdercus species (Heteroptera, Pyrrhocoridae). Comp. Biochem. Physiol. (B) 108: 79-94.

Merlini L. \& NASINI G. 1966: Insect pigments - IV. Pteridines and colour in some Hemiptera. J. Insect Physiol. 12: 123-127.

Poinni A. 2006: Complexity of seminal fluid: a review. Behav. Ecol. Sociobiol. 60: 289-310.

Porcar M., Bel Y., Socha R., NĚMec V. \& Ferré J. 1996: Identification of pteridines in the firebug, Pyrrhocoris apterus (L.) (Heteroptera, Pyrrhocoridae) by high-performance liquid chromatography. J. Chromatography (A) 724: 193-197.

RizKi T. \& Sláma K. 1968: An autosomal recessive gene in Pyrrhocoris. J. Hered. 59: 327-328.

SCHÖFL G. \& TABORSKY M. 2002: Prolonged tandem formation in firebugs (Pyrrhocoris apterus) serves mate-guarding. Behav. Ecol. Sociobiol. 52: 426-433.

Shimizu T. \& KaWASAKI K. 2001: Red-eye mutants in Orius bugs (Heteroptera: Anthocoridae). Appl. Entomol. Zool. 36: $185-187$.
Sláma K. 1998: Autosomal recessive mutations affecting body colour in Pyrrhocoris apterus (Hemiptera: Pyrrhocoridae). Eur. J. Entomol. 95: 17-27.

SlÁmA K. \& Socha R. 1979: Delay of juvenoid action from embryogenesis until metamorphosis unfounded. Acta Entomol. Bohemoslov. 76: 289-299.

SMITH J.H. \& ForREST H.S. 1976: Characterization of an isoxanthopterin binding protein from Oncopeltus fasciatus. J. Insect Physiol. 22: 187-194.

SMITH R.L. \& ForREst H.S. 1969: The pattern of pteridine accumulation in eggs of Pyrrhocoris apterus. J. Insect Physiol. 15: 953-957.

Socha R. 1984: A genetic strain of Pyrrhocoris apterus (Heteroptera) last instar larvae with imaginal-like pigmentation of the wing lobes. Acta Entomol. Bohemoslov. 81: 401-410.

SocHA R. 1987a: Occurrence of precocious adults in the $r l$ (17) strain of Pyrrhocoris apterus (Heteroptera, Pyrrhocoridae). Acta Entomol. Bohemoslov. 84: 10-14.

Sосна R. 1987b: Unusual presence of pigmented granules in the Malpighian tubules in a mosaic mutant of Pyrrhocoris apterus (Heteroptera, Pyrrhocoridae). Acta Entomol. Bohemoslov. 84: 241-245.

SochA R. 1988a: Pale, an autosomal dominant mutation affecting body pigmentation and embryogenesis in Pyrrhocoris apterus (Heteroptera). J. Hered. 19: 131-133.

Socha R. 1988b: Apricot, a new dominant autosomal colour trait in Pyrrhocoris apterus (Heteroptera, Pyrrhocoridae). Acta Entomol. Bohemoslov. 85: 401-407.

SocHA R. 1988c: Altered anteroposterior polarity of micropyle ring formation in eggs of Pyrrhocoris apterus L. (Heteroptera: Pyrrhocoridae). Int. J. Insect Morphol. Embryol. 17: 135-143.

SocHA R. 1993: Pyrrhocoris apterus (Heteroptera) - an experimental model species: a review. Eur. J. Entomol. 90: 241-286.

SochA R. 1995: Selection for an unstable micropterism in Pyrrhocoris apterus (Heteroptera: Pyrrhocoridae). J. Zool. 236: 407-415.

SocHA R. 1997: Genetics of yolk body-color mutation in Pyrrhocoris apterus (Heteroptera: Pyrrhocoridae). Ann. Entomol. Soc. Am. 90: 358-362.

SochA R. 2004: Decreased mating propensity of macropterous morph in a flightless wing-polymorphic insect, Pyrrhocoris apterus (L.) (Heteroptera). Eur. J. Entomol. 101: 539-545.

SocHA R. 2006: Endocrine control of wing morph-related difference in mating success and accessory gland size in male firebugs. Anim. Behav. 71: 1273-1281.

Socha R. \& Hodková M. 1994: Selection for non-diapause in the heteropteran Pyrrhocoris apterus. Hereditas 120: 81-85.

Socha R. \& Hodková M. 2006: Corpus allatum volumedependent differences in accesory gland maturation in longand short-winged males of Pyrrhocoris apterus (Heteroptera: Pyrrhocoridae). Eur. J. Entomol. 103: 27-32.

Socha R. \& Matolín S. 1985: Maternal effect mutation ae responsible for abnormal embryogenesis in Pyrrhocoris apterus (Heteroptera). Acta Entomol. Bohemoslov. 82: 11-21.

SOCHA R. \& NĚMEC V. 1992: Pteridine analysis in five bodycolour mutations of Pyrrhocoris apterus (Heteroptera: Pyrrhocoridae). Acta Entomol. Bohemoslov. 89: 195-203.

SochA R. \& NĚMEC V. 1996: Colouration and pteridine pattern in a new, yolk body mutant of Pyrrhocoris apterus (L.) (Heteroptera: Pyrrhocoridae). Eur. J. Entomol. 93: 525-534.

Socha R. \& Śula J. 1996: Differences in haemolymph proteins in relation to diapause and wing dimorphism in Pyrrhocoris apterus (Heteroptera: Pyrrhocoridae). J. Comp. Physiol. (B) 166: 382-376. 
Socha R. \& Šula J. 2006: Flight muscles polymorphism in a flightless bug, Pyrrhocoris apterus (L.): Developmental pattern, biochemical profile and endocrine control. J. Insect Physiol. 52: 231-239.

Socha R. \& Šula J. 2008: Regulation of the development of flight muscles in long-winged adults of the flightless bug, Pyrrhocoris apterus (Heteroptera: Pyrrhocoridae). Eur. J. Entomol. 105: 575-583.

Socha R. \& ZemeK R. 2000: Wing movement behavior in longand short-winged morphs of flightless bug Pyrrhocoris apterus L. (Heteroptera: Pyrrhocoridae). J. Insect Behav. 13: 741-750.

Socha R., Nedvěd O. \& ZRZavÝ J. 1993: Unstable forewing polymorphism in a strain of Pyrrhocoris apterus (L.) (Heteroptera: Pyrrhocoridae). Ann. Entomol. Soc. Am. 86: 484-489.

Socha R., Šula J. \& ZemeK R. 1997: Feeding, drinking and digestive enzyme activities in long- and short-day females of Pyrrhocoris apterus (Heteroptera). Physiol. Entomol. 22: 161-169.
Socha R., Kodrík D. \& Zemek R. 1999: Adipokinetic hormone stimulates insect locomotor activity. Naturwissenschaften $\mathbf{8 8}$ : $85-86$.

Socha R., Šula J. \& Kodrík D. 2004: Wing morph-related differences in developmental pattern of accessory gland proteins in adult males of Pyrrhocoris apterus (L.) and their endocrine control. J. Insect Physiol. 50: 893-901.

Tram U. \& Wolfner M.F. 1999: Male seminal fluid proteins are essential for sperm storage in Drosophila melanogaster. Genetics 153: 837-844.

Wilson T.G., De Moor S. \& Lei J. 2003: Juvenile hormone involvement in Drosophila melanogaster male reproduction as suggested by the Methoprene-toleratnt ${ }^{27}$ mutant phenotype. Insect Biochem. Mol. Biol. 33: 1167-1175.

WOLFNER M.F. 2002: The gifts that keep on giving: physiological functions and evolutionary dynamics of male seminal proteins in Drosophila. Heredity 88: 85-93.

ŽĎ́́REK J. 1970: Mating behaviour in the bug, Pyrrhocoris apterus L. (Heteroptera): ontogeny and its environmental control. Behaviour 37: 253-268.

Received April 16, 2010; revised and accepted June 10, 2010 